\title{
Speed Reading: Theory, Practice, and Research
}

\author{
Binnan Gao \\ Harvard University, Cambridge, USA
}

\begin{abstract}
This paper reports on training advanced learners of Chinese in five basic reading skills through speed-reading over one semester by using PowerPoint with the time duration function. Both the pre- and post-training tests and the students' questionnaires prove the effectiveness of this training. The questionnaire also reveals important information regarding students' perception of the training and related factors, such as their anxiety level and the influence of unknown words upon their understanding. The scores that students obtained on the tests of the five skills could give a general picture of the difficulty level for each of the trained reading skills.

Keywords: speed reading, reading skills, Chinese advanced learners, unknown words, difficulty hierarchy, pre- and post-tests, questionnaires
\end{abstract}

\section{Introduction}

Reading skills are not introduced systemically in the syllabus for advanced Chinese L2 (second language) learners. The assumption seems to be that the learners will understand a passage well enough as long as they know all the characters, words, and grammar in that passage. Although L2 linguistics knowledge, mainly word knowledge, is the single best predictor of reading comprehension, accounting for up to $30 \%$ of the variance (Landi, 2010), learners also need other domains of linguistic knowledge, such as textual structure and world knowledge, to comprehend the idea of a passage. In addition, without proper reading skills to skim and scan, reading can be less accurate as well as inefficient. The reason for introducing the speed factor into reading comprehension training is that it can force learners to give up reading word by word and use the proper skills, increasing their accuracy in reading comprehension.

\section{Literature Review}

The proposals for reading skills and reading components mainly come from two different but connected perspectives: (1) the instructional and testing perspective; and (2) the research perspective. The early lists of skills proposed by Davis (1968) and Munby (1978) come from the instructional and testing perspective. These lists of skills are concerned with reading as a product; in other words, what understanding is reached by the readers. Their lists are tied into the idea of "levels of understanding", i.e., literal understanding, the understanding of inferred meaning, and critical examination of a text (Alderson, 2001). For example, Davis (1968) defined eight skills, as follows: (1) recalling word meanings; (2) drawing inferences about the meaning of a word in context; (3) finding answers to questions answered explicitly or in paraphrase; (4) weaving together ideas in the content; (5) drawing inferences from the content; (6) recognizing a writer's purpose, attitude, tone, and mood; (7) identifying a writer's technique; and (8) following the structure of a passage. 
Recalling word meanings, finding answers to questions explicitly, weaving together ideas in the content, and following the structure of a passage are all necessary parts of a literal understanding of the text; drawing inferences from the content is understanding between the lines; and recognizing a writer's purpose, attitude, and mood clearly belongs to a critical examination of the text.

The main criticism of defining reading in such a fashion is that analysis of test performance does not reveal separability of skills (Alderson \& Lukmani, 1989; Alderson, 1990a; Alderson, 1990b). However, a skill's approach remains influential in syllabus and material design, as well as the design of language tests (Alderson, 2001).

In the research literature, there are different ways of decomposing the reading construct. A seminal study done by Bernhardt and Kamil (1995) found that 30\% to 38\% of the variance can be accounted for by L2 linguistic knowledge and 10\% to $16 \%$ can be explained by L1 (first language) reading proficiency, with the remaining 50\% unexplained. Within L2 linguistic knowledge, word recognition is the most predictable determiner of reading comprehension, explaining $30 \%$ to $40 \%$ of the variance (Landi, 2010). Studies that tried to prove the existence of variables other than L2 linguistic knowledge and L1 reading proficiency could not explain the variance as much. For example, Leloup (1993) reported an average $1 \%$ variance that could be accounted for by background knowledge, with readers' interest getting an 8\% variance. Landi (2010) found that nonverbal IQ (intelligence quotient), representing general cognitive ability, accounted for at most 3\% of the variance in comprehension ability.

A common view in the research literature is that reading consists of two components: decoding (words recognition) and comprehension. The latter includes parsing sentences, understanding sentences in discourse, building a discourse structure, and integrating this understanding with what one already knows (Gough, Juel, \& Griffith, 1992). DARC (Diagnostic Assessment of Reading Comprehension), developed by Potts and Peterson (1985) and extended by Hannon and Daneman (2001), identified four central comprehension processes: remembering newly read text, making inferences licensed by the text, accessing relevant background knowledge, and making inferences that require integrating background knowledge with the text. Altogether, they could explain $65 \%$ of the variance in the participants' reading comprehension performance (Hannon \& Daneman, 2001).

An alternative is Carver's $(1987,1992)$ view that reading should be seen as having three components: word recognition skills, reading rate or reading fluency, and problem-solving comprehension. Carver (1987) showed that rate fluency abilities increase with reading development. In another study, Carver (1992) examined L1 English college students and distinguished five different reading modes according to different reading purposes or required tasks: scanning (find target word, $600 \mathrm{wpm}$ ), skimming (find transposed words, $450 \mathrm{wpm}$ ), rauding (comprehend complete thoughts in sentences, $300 \mathrm{wpm}$ ), learning (pass multiple choice test, $200 \mathrm{wpm}$ ), and memorizing (recall, 138 wpm). For L1 English-speaking college students, Carver shows that there are optimal reading rates for each of the five reading modes.

The reading components proposed from the research perspective have proved, for the most part, to be independent of each other, with word recognition claimed to be the most important determiner. In addition, the component of comprehension is decomposed in a fashion when reading comprehension is viewed as a process instead of a product. Therefore, reading assessment designed in this way (Potts \& Peterson, 1985; Hannon \& Daneman, 2001) can help diagnose the particular part readers have difficulty with. 


\section{Rational of the Current Project}

Lists of skills from the instructional perspective were chosen in order to train the advanced learners of Chinese, instead of reading components proposed from the research perspective. The reason is that rather than diagnosing which part of the cognitive process gave the students difficulty, the purpose is to train students to master skills to deal with real-life reading tasks, such as locating specific information, generalizing the main idea, and understanding the writer's tone.

Five skills were selected from the reading skills proposed in the literature (Davis, 1968; Grabe, 1991; Munby, 1978). They are: (1) locating specific information; (2) seeing the connection between sentences; (3) locating and summarizing the main idea; (4) following the structure of the narrative and argumentation; and (5) recognizing the writer's purpose, attitude, tone, and mood, as shown in Table 1. Table 1 also presents the types of questions that exercise learners' skills.

As noted in the previous section, these skills are not entirely separable. For example, Skill 2 and Skill 3 both require students to make inferences and summaries. In addition, the types of questions targeting each skill are not exhaustible. For example, to help students build Skill 4, three types of questions were chosen, although there can be more, such as arranging sentences in the correct order.

Table 1

Five Reading Skills Selected for Training Advanced Learners of Chinese

\begin{tabular}{|l|l|l|}
\hline Skills & Text types & Types of questions \\
\hline $\begin{array}{l}\text { 1. Locating specific information } \\
\text { (scanning) }\end{array}$ & $\begin{array}{l}\text { Menus, signs, ads, } \\
\text { directions, timetables }\end{array}$ & Find a specific piece of information. \\
\hline $\begin{array}{l}\text { 2. Seeing connections among } \\
\text { sentences and sub-ideas }\end{array}$ & $\begin{array}{l}\text { Narratives (stories, jokes), } \\
\text { argumentations }\end{array}$ & $\begin{array}{l}\text { Find out what a pronoun refers to. } \\
\text { Complete a paragraph containing conjunctions or adverbs, } \\
\text { such as buguo (however), gen... xiangfan (opposite to), chufei } \\
\text { (unless), etc. }\end{array}$ \\
\hline $\begin{array}{l}\text { 3. Locating main idea and } \\
\text { summarizing sub-ideas into main } \\
\text { idea (skimming) }\end{array}$ & $\begin{array}{l}\text { Narratives (stories, jokes), } \\
\text { argumentations }\end{array}$ & $\begin{array}{l}\text { Find the main idea in the topic sentence. } \\
\text { Summarize sub-ideas into main ideas. }\end{array}$ \\
\hline $\begin{array}{l}\text { 4. Following the structure of a } \\
\text { narrative or an argumentation }\end{array}$ & $\begin{array}{l}\text { Narratives (stories, jokes), } \\
\text { argumentations }\end{array}$ & $\begin{array}{l}\text { Find “what happens initially/then/finally”. } \\
\text { Find out how many points are made. } \\
\text { Insert a sentence in the right place. }\end{array}$ \\
\hline $\begin{array}{l}\text { 5. Recognizing a writer's } \\
\text { purpose, attitude, tone, and mood }\end{array}$ & Narratives, argumentations & $\begin{array}{l}\text { Identify whether the writer is in support of, opposed to, or } \\
\text { ambivalent about a point. }\end{array}$ \\
\hline
\end{tabular}

Why speed reading? Is it too much to expect foreign language learners to read both well and fast? As shown in the literature review section, speed is an important indicator of reading proficiency. A proficient reader reads fast not only because he is able to read the words and sentences quickly but also because he is skillful enough to adjust his attention and reading pace according to the purposes of the reading (Alderson, 2001). In other words, he is able to switch to the different reading modes as defined by Carver (1992), according to the different reading tasks. Both the automaticity with the words and his skills allow him to divert more attention to the task, thereby increasing accuracy. Therefore, introducing the speed factor into the reading tasks can not only help L2 learners become conscious of their reading speed; it can also force L2 learners to give up reading word by word and build up their skills to scan and skim, which will ultimately increase their reading accuracy. 


\section{Practice}

The students, 21 in total, who received the speed reading training were advanced learners of Chinese studying at a prestigious eastern university in the US. They had learned Chinese for two years and a half before the training. Each skill was trained to them in two 10-minute modules in classroom, one at the beginning and one at the end of a two-week period. They were introduced to the skill with the exercises in the first week, and were evaluated on the skill followed by the discussion of the answers in the next week.

Each module contained two phases. The first one was to develop the students' automaticity with words. After new words were taught to them, both the unknown and unfamiliar words were shown to the students with the animation functions of PowerPoint. Students were required to say the English translations of the words as fast as possible. In the second phase, items were presented to students on PowerPoint, and the time duration function of PowerPoint was used to control the time allowed for completing each item.

The set of exercise items and the set of evaluation items are equivalent in terms of length, difficulty level, and time allowed for completion. In each set, there are four to five prompts with five multiple-choice questions. Each prompt is usually either around 50 to 70 characters long followed by one question ranging from 15 to 50 characters long, as shown by Example (1), or 90 to 110 characters long followed by one or two questions, as shown by Example (2). The time allowed to complete the former is 30 to 40 seconds, while the time allowed to complete the longer one is double that, as shown in Table 2. The time length was decided in reference to the reading speed of the students under training, which was 140 characters per minute as measured by a reading comprehension exercise before training. The reading speed in this training was set at 110 to 220 words per minute, a little faster than the students' reading speed before the training, so that they had to give up reading word by word and learn how to skim and scan. For example, the item in Example (1) is 88 characters, with only 30 seconds allowed; this means that the students need to read 176 words per minute if every single word is to be read. However, if the students know that to answer the question, they only need to find the key words, such as shouxian (first), lingwai (in addition), and gengzhongyao de shi (more importantly), it can take them less than 30 seconds to complete. Furthermore, lengths of time given to complete questions were varied, with prompt length and difficulty level of the skills taken into consideration. For example, recognizing a writer's purpose and attitude requires reading the whole prompt and deeper mental work and, therefore, is given longer time than locating information.

Example (1) In characters:

首先, 我喜欢有个性的人, 所以, 你一走上台, 就深深地打动了我。另外, 你能坚持自 己的选择，而不是迎合评委，非常难得。最重要的是，你今天的表现的确非常出色! 所 以，我支持你。(30s)

评委支持这位舞者的原因有几个?
A. -
B. 两
C. 三
D. 四

Romanized:

Shouxian, wo xihuan you gexing de ren, suoyi, ni yi zoushang tai, jiu shenshendedadong-le wo. Lingwai, ni neng jianchi ziji de xuanze, er bushi yinghe pingwei, feichang nande. Zui zhongyao de shi, ni jintian de biaoxian diquefeichang chuse! Suoyi, wo zhichi ni.

Pingwei zhichi zhewei wuzhe de yuanyin you jige? 

A. yi
B. liang
C. san
D. si

Translation:

First of all, I like people with unique characters, therefore, the moment you got unto the stage, you struck me deeply. In addition, you can stick to your choice, but not cater to the taste of the judging committee. That is very rare. Most importantly, your performance today was indeed outstanding. Therefore, I am in support of you.

How many reasons did the judge in the committee have in support of this dancer?
A. yi
B. liang
C. san
D. si

Example (2) In characters:

下午三点的时候，他回到了宿舍。他先给自己泡了一杯浓茶，然后坐到书桌前，拿出笔 记本和笔。他正要写作业的时候, 发现忘记了作业的内容。于是, 他给朋友小李打电话。 打完电话以后, 他突然觉得很饿, 于是吃了一碗方便面。最后, 他又把茶喝光了, 觉得 非常满足! (60s) 他回到宿舍做的第一件事是
A. 拿出笔记本和笔
B. 给自己泡了杯茶
C. 给小李打电话
D. 吃了一碗面 他回到宿舍做的最后一件事是 ?
A. 给小李打电话
B. 吃了一碗面
C. 把茶喝光了
D. 写作业

Romanized:

Xiawu sandian de shihou, ta huidao-le sushe. Ta xian gei ziji pao-le yibei nongcha, ranhou zuodao shuzhuoqian, nachu bijiben he bi. Ta zhengyao xie zuoye de shihou, faxian wangji-le zuoye de neirong. Yushi, ta gei pengyou Xiaoli da dianhua. Dawan dianhua yihou, ta turan juede hen'e, yushi chi-le yiwan fangbianmian. Zuihou, ta you ba cha heguang-le, juede feichang manzu.

Ta huidao sushe zuo de diyi jian shi shi ?

A. nachu bijiben he bi B. gei ziji pao-le bei cha C. gei xiaoli da dianhua D. chi-le yiwan mian Ta huidao sushe zuo de zuihou yijian shi shi

A. gei xiaoli da dianhua B. chi-le yi wan mian C. ba cha heguang-le D. xie zuoye Translation:

Three o'clock in the afternoon, he went back to his dorm. He first made himself a cup of strong tea, and then sitting at the desk, he brought out his notebooks and pens. When he was just about to do his homework, he found that he forgot the content of the homework. Therefore, he called his friend Little Li. After hanging up, he suddenly felt very hungry, and therefore he ate a bowl of instant noodles. Finally, he drank up his cup of tea, and felt very happy and content!

The first thing that he did when he got back dorm was

A. took out his notebook B. made himself a cup of tea C. called Little Li D. ate a bowl of noodles The last thing that he did when he got back dorm was

A. called Little Li B. ate a bowl of noodles C. drank up his cup of tea D. wrote his homework 
Table 2

The Length of Prompt and Its Question and Time Allowed for Items of Five Different Reading Skills

\begin{tabular}{llllll}
\hline & Skill 1 & Skill 2 & Skill 3 & Skill 4 & Skill 5 \\
& Locating info & Seeing connections & $\begin{array}{l}\text { Summarize } \\
\text { main idea }\end{array}$ & $\begin{array}{l}\text { Following structure } \\
\text { Recognizing writer's } \\
\text { purpose, attitudes, and mood }\end{array}$ \\
\hline $\begin{array}{l}\text { N of prompts } \\
\text { N of questions }\end{array}$ & $4 *$ & $4^{*}$ & $5^{*}$ & $4^{*}$ & $5 *$ \\
$\begin{array}{l}\text { Length of prompts (N of } \\
\text { char) }\end{array}$ & $50-70$ & $50-70$ & 5 & 5 & $50-70$ \\
$\begin{array}{l}\text { Length of questions and } \\
\text { options (N of char) }\end{array}$ & $15-30$ & $25-40$ & $50-90$ & $50-70$ & $20-30$ \\
Time (sec) & 35 & 40 & $35-50$ & $30-40$ & 40 \\
\hline
\end{tabular}

Notes. N: number; Char: character; Sec: second; * indicates that there is one prompt that is twice the length of the prompt indicated in the table. Time allowed for it and its question is twice as much as that allowed for the shorter prompts; ** indicates that there are two prompts that are twice the length of the prompt indicated in the table. Time allowed for it and its question is twice as much as that allowed for the shorter prompts.

Since word knowledge is crucial to reading comprehension for foreign language learners, the words used were strictly controlled. The words used in the items are mostly in the range of the 0 to 3,000 vocabulary frequency list of The Syllabus of the Graded Vocabulary and the Graded Characters for Chinese Proficiency Test, which is less than the vocabulary size of the students under training, who had learned 3,500 words before the training. The new words were taught before the students worked on the items as said before. It should also be mentioned that $50 \%$ of the items were written on the basis of the items of the reading sections of Chinese Proficiency Test (HSK) level 4 and 50\% were written from scratch.

\section{Research}

Pre- and post-tests, which included five items that respectively tested the five selected skills, were developed and administered to the students before and after the training to measure their gains. The two tests were equivalent in terms of length and difficulty levels, and they had the same format as that of the exercises and evaluations used in the training. The students were also given an eight-item questionnaire at the end of the training. In it, they rated on a scale of 1 to 5 (with 5 being the strongest and 1 the weakest) how much they agreed with statements designed to find out: (1) their gains; (2) the relationship between knowledge of words and their understanding; and (3) other factors of the exercise and evaluation items.

\section{Results of Gains According to Pre- and Post-tests}

The 21 students who received the speed reading training throughout the semester performed more accurately on their post-test, as indicated by the accuracy rates. The paired-sample $t$-test indicates that these students performed statistically significantly better in the post-test than in the pre-test, as shown in Table 3.

Table 3

The Paired-Sample T-test of Accuracy Rates of Pre- and Post-tests

\begin{tabular}{cccccc}
\hline \multicolumn{5}{c}{ Post-test $(\mathrm{N}=5)$} \\
\hline $\mathrm{M}(\%)$ & $\mathrm{SD}$ & $\mathrm{M}(\%)$ & $\mathrm{SD}$ & $t$-test & $d f$ \\
70 & 0.12 & 80 & 0.07 & $-3.08^{* *}$ & 20 \\
\hline
\end{tabular}

Notes. ${ }^{* *} p<0.01 ; \mathrm{M}=$ mean; $\mathrm{SD}=$ standard deviation.

\section{Results of the Questionnaire}

As shown in Table 4, according to the percentage of students who "strongly agreed" with a statement, i.e., 
those who chose 4 or 5 in the scale of 1 to 5 , and the average of their ratings, they strongly agreed that this speed reading training helped with their reading comprehension ability and speed. They also became more confident by the end of the training. Seventy-one point four percent of the students "strongly agreed" with the statements, granting these statements the highest level of agreement, and the average of their ratings of these statements range from 7.52 to 7.81 in the scale of 1 to 10, the highest ratings among all statements. For some reason, they did not agree that they utilized these skills in other reading materials as much as they agreed with the other statements about the effectiveness of the training. Both the percentage of the students who "strongly agreed" with the statement and the average of their ratings were the lowest among ratings of all statements regarding the effectiveness of the training.

The questionnaire also shows that the students did not have much difficulty decoding the learned characters and words, since less than half of them strongly agreed with the statement that says the opposite, and the average of their ratings was only slightly above 6 on a scale of 1 to 10 . However, compared to the above rating, the students felt stronger about the effect of unknown words on their performance in reading comprehension, since around $60 \%$ of the students "strongly agreed" with the statement, and the average of their ratings reached 7.52, the same as the average of their ratings on most of the statements regarding the training's effectiveness.

As for the other factors, the students felt OK about the speed of the slides, and their anxiety level was not very high. Fewer than half of the students agreed with the statements regarding their anxiety level and the speed of the slides, and the average of their ratings was between 6 and 7, almost the lowest of all ratings on the statements.

Table 4

Students' Feedback Collected From the Questionnaire After the Training

\begin{tabular}{|c|c|c|c|c|}
\hline & & $\begin{array}{l}\text { Number and percentage of } \\
\text { learners who strongly agree* } \\
(\mathrm{N}=21)\end{array}$ & $\begin{array}{l}\text { Average } \\
\text { (Transformed on a } \\
\text { scale of } 1 \text { to 10) }\end{array}$ & $\begin{array}{l}\text { Standard } \\
\text { deviation }\end{array}$ \\
\hline \multirow[t]{4}{*}{$\begin{array}{l}\text { Effectiveness of the } \\
\text { training }\end{array}$} & $\begin{array}{l}\text { Help with reading comprehension } \\
\text { in general }\end{array}$ & $15(71.4 \%)$ & $\begin{array}{l}3.76 \\
(7.52)\end{array}$ & 0.70 \\
\hline & Help with speed in general & $15(71.4 \%)$ & $\begin{array}{l}3.90 \\
(7.81)\end{array}$ & 1.00 \\
\hline & More confident & 15 (71.4\%) & $\begin{array}{l}3.76 \\
(7.52)\end{array}$ & 1.00 \\
\hline & $\begin{array}{l}\text { Utilize the skills in other reading } \\
\text { materials }\end{array}$ & 9 (42.9\%) & $\begin{array}{l}3.33 \\
(6.66) \\
\end{array}$ & 1.06 \\
\hline $\begin{array}{l}\text { Relationship between } \\
\text { words and }\end{array}$ & $\begin{array}{l}\text { Have difficulty figuring out learned } \\
\text { words }\end{array}$ & $10(47.6 \%)$ & $\begin{array}{l}3.19 \\
(6.38)\end{array}$ & 1.33 \\
\hline comprehension & Unknown words effect & $13(61.9 \%)$ & $\begin{array}{l}3.76 \\
(7.52) \\
\end{array}$ & 1.14 \\
\hline \multirow[t]{2}{*}{ Other factors } & Slides went too fast & $9(42.9 \%)$ & $\begin{array}{l}3.00 \\
(6.00)\end{array}$ & 1.14 \\
\hline & Very anxious & $9(42.9 \%)$ & $\begin{array}{l}3.33 \\
(6.66)\end{array}$ & 1.15 \\
\hline
\end{tabular}

Notes. * indicates that learners who chose 5 and 4 in the survey; N: number of students.

\section{Other Results}

Since the time allowed for completing the test items of the five reading skills varied not only according to the length of the prompt but also according to the conjectured difficulty level, the accuracy rates of the tests of the five skills (as shown in Table 5) cannot accurately reflect the difficulty of these skills. For example, Skill 4 (following structure) was given only 30 seconds per item, while Skill 2, Skill 4, and Skill 5 were all given 40 seconds per item. The accuracy rate of Skill 4 might have increased if the students were allowed more time. On 
the other hand, although the time allowed for completing the test item for Skill 1 (locating specific information) was given 35 seconds, its accuracy rate was the highest.

Despite all this, Table 5 still gives us a picture, though not accurate, of the difficulty levels of these five selected skills. It seems that Skill 1, which requires the lower-level skills of word recognition and scanning, was the easiest for the students, while Skill 2 (seeing connections among sentences), which requires the deeper mental work, was the most difficult. Skill 3, Skill 4, and Skill 5 were in between. Skill 5 demands deeper mental work as well. While some questions tap Skill 3 and Skill 4 in ways that require abilities similar to those demanded by Skill 1, other questions that address these skills require deeper mental work. For example, for Skill 4, questions like finding what has been done first, second, and last, which are introduced in the passages by the words "first", "second", and "last" were easy for the students while inserting a sentence in the proper place in a paragraph can be difficult.

Table 5

The Accuracy Rates of the Tests of Five Selected Skills

\begin{tabular}{|c|c|c|c|c|c|}
\hline & $\begin{array}{l}\text { Skill } 1 \\
\text { Locating info }\end{array}$ & $\begin{array}{l}\text { Skill } 2 \\
\text { Seeing connections }\end{array}$ & $\begin{array}{l}\text { Skill } 3 \\
\text { Summarizing } \\
\text { main idea }\end{array}$ & $\begin{array}{l}\text { Skill } 4 \\
\text { Following structure }\end{array}$ & $\begin{array}{l}\text { Skill } 5 \\
\text { Recognizing writer's purpose, } \\
\text { attitudes, and mood }\end{array}$ \\
\hline Accuracy rate (\%) & 92 & 62 & 88 & 80 & 88 \\
\hline $\begin{array}{l}\text { Standard } \\
\text { deviation }\end{array}$ & 0.06 & 0.13 & 0.09 & 0.08 & 0.07 \\
\hline
\end{tabular}

\section{Discussion}

The statistically significant difference between the students' pre- and post-test performances proves that at the end of the training, the students improved their speed-reading skills. However, these results might not accurately reflect the extent of the students' improvement resulting from the training alone, since the students also got other opportunities to exercise their reading skills throughout the semester and might have brought the skills they learned through other activities to this training.

Carver's theory can help, to some extent, explain why the students did not strongly agree that they utilized the skills in other reading materials. In the course they were taking, they also did an intensive reading of a text in class, with the guidance of teachers, for the purpose of studying the grammar and sentence structures and comprehending the text. Once every other week, they read a 1,000- to 1,500-character story on their own after class. It is possible that since the former requires the studying mode, there is not as much need for the students to speed-read and, therefore, to utilize these learned skills. The number of new words in the latter was not controlled and the students might focus on figuring out the meaning of each sentence, not realizing they were using the skills even if they might. If the students had been given reading materials of different nature and with the number of new words controlled, we would be able to find out whether the reading skills, especially Skill 2, Skill 3, Skill 4, and Skill 5, which the students learned through reading the shorter passages in the training, to longer and more complicated passages and, as a result, be able to comprehend better and faster as we wished. It will take more refined approach in the future to find out whether the reading skills that the student learn through speed-reading can be carried out to other reading materials.

The students reported that they did not have difficulty figuring out the meaning of learned words and that decoding the learned words did not affect their performance. This shows that students at this level have 
developed a certain degree of automaticity with the characters and words, which is the first step toward reading well and fast. They also reported that the words that they did not learn affected their reading comprehension significantly, although the anticipated unknown words were taught to them before they started to do the items. This is consistent with the research findings that say word recognition is a strong predictor of reading comprehension for L2 learners. In other words, L2 learners or even native speakers would not be able to use the skills or to read fast if there are too many words they do not know. For example, SHEN (2005) indicated that for beginning L2 learners, an increase of $1 \%$ of unknown words in the reading text could bring about a decrease in the reading comprehension rate from $2 \%$ to $4 \%$.

Since the time allowed to complete the items for the five selected reading skills was not the same, the accuracy rates of the five skills could not reflect their difficulty levels. However, we can still see that a skill that requires lower mental ability, such as scanning, is easier for students than those that require higher mental ability, such as making inferences, generalizing main ideas, and understanding the writer's purpose. Among the skills that require higher mental abilities, it is hard to say which is more difficult, since the difficulty level of each skill also depends on the type of questions used to test it. For example, for Skill 3 (generalizing the main idea) a question like finding out the main idea in the topic sentence requires locating specific information type of skill (Skill 1) and is probably easy for the learners. Questions like those regarding the summary of sub-ideas into a main idea require not only the ability to locate specific information (Skill 1), which in the test was introduced by words like shouxian (first) and di'er (second), but also a kind of inference-making ability, namely seeing connections among sentences throughout the text (Skill 2). Therefore, this type of question can be harder than finding the main idea in the topic sentence. It can be imagined that if the students are required to summarize main ideas of a paragraph with sub-ideas that are not so obvious, the difficulty level will increase. Hence, this project proves one more time that not only are the skills proposed from the instructional perspective inseparable, but also that it is almost impossible to provide a difficulty hierarchy for the skills, given that skill difficulty varies with the mental challenge demanded by the different tasks.

\section{Conclusions}

The results of the pre- and post-tests prove the effectiveness of the training. According to the questionnaires collected at the end of the training, the students claimed that the training helped improve their reading speeds and reading comprehension abilities in general. They also become more confident by the end of the training. However, it needs further research to decide whether the skills that the learners have learned through the speed-reading can be employed to longer passages.

According to the questionnaires, the students' anxiety level and the speed of the slides were both in the OK range, indicating that the speed and difficulty of the items were set right for the advanced learners of Chinese with knowledge of 3,500 characters who read 140 words per minute. The students strongly agreed with the statement that unknown words affected their performance, confirming the results of previous research that vocabulary knowledge is the single best predictor for reading comprehension.

The scores that students obtained on the tests of the five skills reveal that the skill that requires the lower-level mental work, such as locating specific information, is easier for the students than the skills that demand deeper mental work, such as seeing connections among sentences, and generalizing main ideas. Among the latter, following the structure, generalizing main ideas, and seeing the attitude and mood of the author are 
easier than seeing connections among sentences. However, we cannot give a difficulty hierarchy of the reading skills in this study, since the difficulty of most of the skills is also dependent on the questions that tap it.

\section{References}

Alderson, J. C. (1990a). Testing reading comprehension skills (Part One). Reading in a Foreign Language, 6(2), 425-438.

Alderson, J. C. (1990b). Testing reading comprehension skills (Part Two). Reading in a Foreign Language, 7(1), 465-503.

Alderson, J. C. (2001). Assessing reading. Cambridge: Cambridge University Press.

Alderson, J. C., \& Lukmani, Y. (1989). Cognition and reading: Cognitive levels as embodied in test questions. Reading in a Foreign Language, 5(2), 253-270.

Bernhardt, E., \& Kamil, M. L. (1995). Interpreting relationships between L1 and L2 reading: Consolidating the linguistic threshold and the linguistic interdependence hypotheses. Applied Linguistics, 16(1), 15-34.

Carver, R. P. (1987). Technical manual for the rate level test. Kansas City, M.O.: Revrac Publications.

Carver, R. P. (1992). Theory, research and implications. Journal of Reading, 36(2), 85-95.

Davis, F. B. (1968). Research in comprehension in reading. Reading Research Quarterly, 3, 499-545.

Gough, P., Juel, C., \& Griffith, P. (1992). Reading, speaking and the orthographic cipher. In P. Gough, L. Ehri, \& R. Treiman (Eds.), Reading acquisition. Hillsdale, N.J.: L Erlbaum.

Grabe, W. (1991). Current developments in second language reading research. TESOL Quarterly, 25(3), 375-406.

Hannon, B., \& Daneman, M. (2001). A new tool for measuring and understanding individual differences in the component processes of reading comprehension. Journal of Educational Psychology, 93(1), 103-128.

Landi, N. (2010). An examination of the relationship between reading comprehension, higher-level and lower-level reading sub-skills in adults. Read and Writing, 23(6), 701-717.

Leloup, J. W. (1993). The effect of interest level in selected text topics on second language reading comprehension (Unpublished doctoral dissertation, The Ohio State University, Columbus).

Munby, J. (1978). Communicating syllabus design. Cambridge: Cambridge University Press.

Potts, G. R., \& Peterson, S. B. (1985). Incorporation versus compartmentalization in memory for discourse. Journal of Memory and Language, 24, 107-118.

SHEN, H. H. (2005). Linguistic complexity and beginning-level L2 Chinese reading. Journal of the Chinese Language Teachers Association, 40, 1-28.

The Syllabus of the Graded Vocabulary and the Graded Characters for Chinese Proficiency Test. (2001). Beijing: Economical Science Publishing House. 